\title{
Population Normative Data of the Moroccan Arabic Version of Three Components of the 10/66 Dementia Research Group Cognitive Test Battery; with Moroccan Illiterate and Semi-Illiterate Subjects
}

\author{
Asmaa Oumellal1,2, Mustapha El Alaoui Faris ${ }^{1,2,3}$, Maria Benabdeljlil1,2,3 \\ ${ }^{1}$ Faculty of Medicine and Pharmacy, University Mohammed V, Rabat, Morocco \\ ${ }^{2}$ Department of Neurology and Neuropsychology, Specialty Hospital, Rabat, Morocco \\ ${ }^{3}$ Alzheimer's Day Center of Rabat, Rabat, Morocco \\ Email: oumellal.asmaa@gmail.com
}

How to cite this paper: Oumellal, A., El Alaoui Faris, M. and Benabdeljili, M. (2019) Population Normative Data of the Moroccan Arabic Version of Three Components of the 10/66 Dementia Research Group Cognitive Test Battery; with Moroccan Illiterate and Semi-Illiterate Subjects. Advances in Alzheimer's Disease, 8, $1-14$.

https://doi.org/10.4236/aad.2019.81001

Received: March 14, 2019

Accepted: March 26, 2019

Published: March 29, 2019

Copyright $\odot 2019$ by author(s) and Scientific Research Publishing Inc. This work is licensed under the Creative Commons Attribution International License (CC BY 4.0).

http://creativecommons.org/licenses/by/4.0/ (c) (i) Open Access

\begin{abstract}
The aim of this study was to provide normative data of the Moroccan Arabic version of the 10/66 Dementia Research Group cognitive test battery and to explore the effects of age, education/illiteracy, and gender on the performance of these tests. One hundred healthy subjects (67 illiterates and 33 semi-illiterates) participated in this study. None of the participants had serious medical, psychiatric, or neurological disorders including dementia. The protocol included the administration of three components of the 10/66 Dementia Research Group cognitive test battery; Community Screening Instrument for Dementia (CSI "D", generating the COGSCORE measure of global function), and the Consortium to Establish a Registry for Alzheimer's Disease (CERAD) verbal fluency (VF), word list memory (WLM, immediate recall) tests. All the test scores were not significantly influenced by sex and age. There was no significant effect of education/illiteracy on the CERAD verbal fluency (VF) and Word List Memory (immediate recall) test scores, but a weakly significant ( $\mathrm{p}$ $<0.05$ ) effect on the CSI "D" COGSCORE performance. These normative data will be useful for clinical interpretations of the three components of the 10/66 Dementia Research Program protocol in illiterate and semi-illiterate Moroccan subjects with cognitive disorders.
\end{abstract}

\section{Keywords}

10/66 Cognitive Test Battery, Normative Study, Age, Education, Illiteracy 


\section{Introduction}

Around the world, there will be one new case of dementia every 3 seconds; 50 million people worldwide are living with dementia in 2018. This number will more than triple to 152 million by 2050 [1]. Nearly $60 \%$ of people with dementia currently live in low- and middle-income countries and most new cases (71\%) are expected to occur in those countries [1] [2] [3] [4].

Using the estimated aging indices for the years 2030 and 2050, Morocco with an aging index ranging from 41.7 percent to 72.8 percent in 2030, is considered rapidly aging. Despite the presence of aging policies in Morocco, almost half of the policies appear to still be in the planning or initiated phases [5].

The Office of the High Commissioner for the Plan of Morocco estimates that the population of older people increased more than three and a half times between 1960 and 2014, from 836,000 to 3,200,000 [6]. Its rate in the total population passed from $4.8 \%$ in 1980 to $12.7 \%$ in 2018 . This rate is predicted to rise more rapidly to $26.5 \%$ in 2050 [7] [8] [9].

The elderly Moroccan population is mostly illiterate (70\%), only $2.5 \%$ have been high level of education. Illiteracy of the elderly is more pronounced in rural areas $(85.9 \%)$ than urban areas $(58.2 \%)$. The gap between male and female illiteracy among the adult population is greater (male illiteracy rate 53.5 percent, female 85.0 percent) [6].

Cognitive decline and dementia have a high individual impact and are strongly age-associated. Variations in the prevalence of dementia within different ethnic groups have been reported worldwide, and a number of reviews have provided a picture of epidemiological studies in dementia research [3] [10]. However, little is known about the prevalence of dementia within the Moroccan population. In the World Alzheimer Report 2015 [3], the highest standardized prevalence was those in North Africa/Middle East-Egypt (8.7\%), (applied to Egypt, Iraq, Morocco, Yemen, Algeria and Turkey).

There is one published study which investigated the demographic profile and etiologies of dementia in the Memory Center of Rabat (Morocco) [11]. The study shows a large diversity of etiologies in dementia. The mechanism was degenerative in 328 cases (58.5\%) including 287 Alzheimer's Disease (AD), vascular in 95 cases (16.9\%), mixed in 42 cases, infectious in 33 cases and inflammatory in 18. Other etiologies were found in 35 cases, and dementia was of undetermined cause in 10 cases. In the study by Sweeney and colleagues study, vascular dysfunction is described as the disregarded partner of Alzheimer's disease, an important early event in $\mathrm{AD}$ pathophysiology [12].

According to the latest WHO data published in 2017 [13], Alzheimer/Dementia, listed as the underlying cause of death, accounts for nearly 9847 deaths in Morocco. That's about 1 of every 18 deaths.

There is as yet no innovative treatment for the condition, and so prompt detection and diagnosis of dementia is very important [14] [15]. Regular physical activity and management of cardiovascular risk factors (diabetes, obesity, smok- 
ing, and hypertension) reduce the risk of cognitive decline and may reduce the risk of dementia. There is sufficiently strong evidence to conclude that a healthy diet and lifelong learning/cognitive training may also reduce the risk of cognitive decline [16] [17] [18].

Cognitive tests covering multiple domains are an essential component of a definitive dementia diagnostic assessment for the purposes of establishing the criterion of decline in at least two domains of cognitive function, including memory [19].

The performance in neuropsychological tests is influenced by educational and cultural factors [20]; illiterate people have difficulty in responding to tests that require reading and writing skills or copying complex figures, even though they may have a normal level of cognitive function [14].

The current tests for screening and diagnosing dementia in Morocco are an adaptation of the Western version that does not take into consideration the presence of illiteracy in the Moroccan population. Accordingly, any subject with little or no education but without dementia is likely to have difficulties in properly responding to some of the questions on these tests. Therefore, accurate identification and diagnosis of dementia among illiterate elderly subjects are problematic when using these tests [14].

This study was conducted to translate to Moroccan Arabic language, and to harmonize and test the cognitive test battery used in the 10/66 studies comprising tests of general cognitive function, verbal fluency and immediate verbal recall [21]. It also aimed to present the normative preliminary information, explore the effects of age, education/illiteracy, and gender on the performance of these three tests on illiterate and semi-illiterate Moroccan subjects.

\section{Method}

\subsection{Ethics}

All subjects were informed about the objectives and procedures involved in the study, and provided oral informed consent prior to the interviews and tests.

\subsection{Participants and Test Procedure}

The geographic study area was Khémisset, a province in the Moroccan economic region of Rabat-Salé-Kénitra, with a population of 131,542 recorded in the 2014 Moroccan census [22]. This town was founded in 1924 on the site of a military outpost on the road from Rabat to Fes. Khemisset has a consistent supply of electrical power, water and sewage management, roads, modern communication technology, and access to healthcare services.

The elderly illiterates and semi-illiterates in Khemisset (Zemmour Tribes) are a semirural population. They speak the Central Atlas Tamazight dialect, and Moroccan Arabic (known as Darija), thereby creating a bilingual town. Now a provincial capital Khemisset is also the capital of the confederation of the Berber-speaking Zemmour Tribes. Semi-illiterates did receive some years of educa- 
tion though they did not complete primary education in school or in Koranic Schools).

Interdisciplinary teams collaborated on the translation and adaptation of the 10/66 Dementia Research Group cognitive test battery. The team members included the disciplines of neurology and neuropsychology. The teams reviewed and discussed each item to be harmonious with the culture and the language during the period from 2016 to 2017. The instrument was tested for acceptability with 10 elderly volunteers. The results were evaluated, and following minor revisions, the instrument was used in a pilot study with 30 volunteers living independently in a community similar in demographic characteristics to the normative population throughout the same period of time.

Sampling strategies were determined by the available resources. Selected individuals were initially contacted to arrange a home visit to conduct the protocol by only one qualified neuropsychologist. After obtaining informed consent, three components of the 10/66 Dementia Research Group cognitive test battery were conducted inside the participants' homes. This process was followed until 100 individuals (they are all volunteers and non-remunerated) were enrolled during the period from January 2018 to December 2018. There were no refusals.

One hundred healthy subjects living in a semirural community participated in this study (43 males and 57 females). All of the participants were aged between 45 and 90 years were classified into three groups based on age (45 - 55 years, 56 65 years and 66 - 90 years) and two groups based on educational level (67 illiterates and 33 semi-illiterates) (Table 1). None of the participants had serious medical, psychiatric, or neurological disorders including dementia. Subjects who

Table 1. Sociodemographic characteristics of participants.

\begin{tabular}{cc}
\hline Age in years & Number of subjects \\
\hline $45-55$ years & 33 \\
56 - 65 years & 31 \\
66 - 90 years & 100 \\
Total (n) & Number of subjects \\
Sex & 57 \\
Female & 43 \\
Male & 100 \\
Total (n) & Number of subjects \\
Education & 67 \\
Illiterates & 33 \\
semi-illiterates & 100 \\
Total (n) &
\end{tabular}


were illiterate due to learning and developmental difficulties were excluded fromthis study. All the participants spoke Amazigh and Moroccan Arabic languages except 10 Arabic monolingual subjects.

\subsection{Measurements}

For this analysis, we considered the following socio-demographic measures as independent variables: participants' age divided into three groups based on age ( 45 - 55 years, 56 - 65 years and $\geq 66$ years), sex, and education level divided into two groups (67 illiterates and 33 semi-illiterates did not complete primary).

The 10/66 Dementia Research Program was set up to facilitate research in low and middle-income countries, to generate site-specific norms for the cognitive test battery [21], comprising general cognitive function (CSI "D" COGSCORE) developed by the Ibadan-Indianapolis study group [23], verbal fluency and immediate and delayed verbal recall from the Consortium to Establish a Registry for Alzheimer's Disease (CERAD), and to provide data that can be used for public health and service planning [21]. In this study we use only three components of the 10/66 Dementia Research Program protocol:

1) The Community Screening Interview for Dementia (CSI'D') was developed as a screening instrument for dementia to be used in cross-cultural studies. It consists of two components, a Global Cognitive Function (CSI'D' COGSCORE) for illiterate and literate populations and an informant interview regarding performance in everyday life [23]. This instrument has now been used in several sites and with different populations; including the African Americans in Indianapolis, Indiana, USA; Yoruba in Ibadan, Nigeria; Cree Indians in Manitoba, Canada; English-speaking Canadians in Winnipeg; and Jamaicans of African extraction in Kingston, Jamaica [24].

CSI "D" was further validated in India, China and South East Asia, Latin America and the Caribbean and Africa, as part of the 10/66 Dementia Diagnosis Protocol [25].

2) The Word List Memory (WLM) from the CERAD: the 10-word list test, in the learning phase testing immediate recall. The list is read out to the participants, who are then asked to recall straight away the words that they remember. This process is repeated three times, giving an Immediate Word Recall score out of 30 [21].

3) The Verbal Fluency (VF): the animal naming Verbal Fluency task [12] from the CERAD is administered as part of the CSI " $D$ ", however, it is given very little credit within the algorithm for calculating the total CSI " $D$ " score. The participants are encouraged to name as many different animals as they can within one minute of time. The instructions read out to the participant stipulate: "think of any kind of animal in the air, on land, in the water, in the forest, all the different animals?". If the participant stops before the allotted time has elapsed they are encouraged to continue. The score is one point for each valid name [21]. 


\section{Statistical Analysis}

Age, education/illiteracy and sex were coded as categorical variables. Age was categorized into three groups ( 45 - 55 years, 56 - 65 years, and 66 - 90 years); education/illiteracy was categorized into two groups of "illiterates $=0$, semi-illiterates = 1 - 5 years"; and sex into two groups of "male and female," respectively.

Analysis of variance (ANOVA) was also performed to determine any main effects and interactions between age (45 - 55 years, 56 - 65 years and 66 - 90 years), education/illiteracy ("illiterates $=0$, semi-illiterates $=1-5$ years") and sex in the test. Participants' age, sex and education data were described. Means and standard deviations (SD) for each of the three cognitive tests were calculated by age, sex and education. All of the analysis was performed using IBM SPSS Software. The cut-off for statistical significance was set at $\mathrm{p}<0.05$.

\section{Results}

\section{Demographic Characteristics of Subjects}

The demographic characteristics of the 100 subjects who completed the three cognitive tests are given in Table 1 . The mean age of the male subjects (61.2 \pm 5.6 years) differs from that of the female subjects ( $60.5 \pm 10.4$ years). The mean number of years of education was higher in the male group ( $1.5 \pm 1.9$ years) than in the female group $(0.3 \pm 0.9$ years). The proportion of illiterate subjects differed between males (49\%) and females (81.0\%).

Effects of age, education/illiteracy, and sex on the three components of the $10 / 66$ cognitive test battery.

Tables 2-4 present normative data: Stratified means and standard deviations for the three components of the 10/66 cognitive test battery.

In the CSI "D" COGSCORE, the younger group of Male subjects (45 - 55 years) performed slightly less well than older group subjects. Illiterate Male subjects performed slightly better than semi-illiterate subjects in the same range of age group (66 - 90 years). The younger and semi-illiterate Female subjects slightly outperformed the older and illiterate. In the total score of the CSI " $D$ " COGSCORE, males performed marginally than females.

The CSI "D" COGSCORE performances are not significantly influenced by sex and age, but the effect of education/illiteracy weakly significant $(p<0.05)$, as indicated in Table 5 (ANOVA tests).

In the CERAD Word List Memory, the younger illiterate group of male subjects (45 - 55 years) performed slightly less than older illiterate group (56 - 65 years). Illiterate male subjects performed slightly better than semi-illiterate subjects in the same range of age group (56 - 65 years). Illiterate female subjects in the 45 - 55 years age group slightly outperformed the semi-illiterate. In the total scores of the CERAD Word List Memory, females performed marginally better than males. 
Table 2. Mean (SD) scores for global cognitive function (CSI "D" COGSCORE) by demographic status.

\begin{tabular}{|c|c|c|c|c|c|}
\hline Sex & Age & Education & Mean & $\begin{array}{c}\text { Standard } \\
\text { deviations }\end{array}$ & Number \\
\hline \multirow{12}{*}{ Male } & & Illiterates & 29.8 & 1.6 & 4 \\
\hline & $45-55$ & semi-illiterates & 30.9 & 0.5 & 4 \\
\hline & & Total & 30.3 & 1.2 & 8 \\
\hline & & Illiterates & 31.0 & 1.0 & 10 \\
\hline & $56-65$ & semi-illiterates & 31.5 & 1.0 & 13 \\
\hline & & Total & 31.3 & 1.0 & 23 \\
\hline & & Illiterates & 30.8 & 1.2 & 7 \\
\hline & $66-90$ & semi-illiterates & 29.9 & 2.6 & 5 \\
\hline & & Total & 30.4 & 1.8 & 12 \\
\hline & & Illiterates & 30.7 & 1.2 & 21 \\
\hline & Total & semi-illiterates & 31.0 & 1.5 & 22 \\
\hline & & Total & 30.9 & 1.4 & 43 \\
\hline \multirow{12}{*}{ Female } & & Illiterates & 30.0 & 1.1 & 18 \\
\hline & $45-55$ & semi-illiterates & 31.0 & 1.6 & 7 \\
\hline & & Total & 30.3 & 1.3 & 25 \\
\hline & & Illiterates & 29.5 & 1.2 & 11 \\
\hline & $56-65$ & semi-illiterates & 30.8 & 1.1 & 2 \\
\hline & & Total & 29.7 & 1.2 & 13 \\
\hline & & Illiterates & 28.6 & 2.2 & 17 \\
\hline & $66-90$ & semi-illiterates & 30.8 & 0.23 & 2 \\
\hline & & Total & 28.8 & 2.2 & 19 \\
\hline & & Illiterates & 29.4 & 1.7 & 46 \\
\hline & Total & semi-illiterates & 30.9 & 1.3 & 11 \\
\hline & & Total & 29.7 & 1.7 & 57 \\
\hline \multirow{12}{*}{ Total } & & Illiterates & 29.9 & 1.2 & 22 \\
\hline & $45-55$ & semi-illiterates & 31.0 & 1.3 & 11 \\
\hline & & Total & 30.3 & 1.3 & 33 \\
\hline & & Illiterates & 30.2 & 1.3 & 21 \\
\hline & $56-65$ & semi-illiterates & 31.4 & 1.0 & 15 \\
\hline & & Total & 30.7 & 1.3 & 36 \\
\hline & & Illiterates & 29.3 & 2.2 & 24 \\
\hline & $66-90$ & semi-illiterates & 30.1 & 2.1 & 7 \\
\hline & & Total & 29.5 & 2.2 & 31 \\
\hline & & Illiterates & 29.8 & 1.7 & 67 \\
\hline & Total & semi-illiterates & 31.0 & 1.4 & 33 \\
\hline & & Total & 30.2 & 1.7 & 100 \\
\hline
\end{tabular}


Table 3. Mean (SD) scores for CERAD word list memory (immediate recall) test by demographic status.

\begin{tabular}{|c|c|c|c|c|c|}
\hline Sex & Age & Education & Mean & $\begin{array}{c}\text { Standard } \\
\text { deviations }\end{array}$ & Number \\
\hline \multirow{12}{*}{ Male } & & Illiterates & 13.2 & 0.9 & 4 \\
\hline & $\begin{array}{c}45-55 \\
\text { Years }\end{array}$ & semi-illiterates & 15.7 & 3.7 & 4 \\
\hline & & Total & 14.5 & 2.8 & 8 \\
\hline & & Illiterates & 14.2 & 4.4 & 10 \\
\hline & $\begin{array}{c}56-65 \\
\text { Years }\end{array}$ & semi-illiterates & 12.7 & 2.7 & 13 \\
\hline & & Total & 13.3 & 3.5 & 23 \\
\hline & & Illiterates & 13.7 & 3.4 & 7 \\
\hline & $\begin{array}{c}66-90 \\
\text { Years }\end{array}$ & semi-illiterates & 14.2 & 3.7 & 5 \\
\hline & & Total & 13.9 & 3.4 & 12 \\
\hline & & Illiterates & 13.8 & 3.5 & 21 \\
\hline & Total & semi-illiterates & 13.6 & 3.2 & 22 \\
\hline & & Total & 13.7 & 3.3 & 43 \\
\hline \multirow{12}{*}{ Female } & & Illiterates & 15.9 & 3.9 & 18 \\
\hline & $\begin{array}{c}45-55 \\
\text { Years }\end{array}$ & semi-illiterates & 14.3 & 3.3 & 6 \\
\hline & & Total & 15.5 & 3.8 & 24 \\
\hline & & Illiterates & 13.2 & 3.2 & 11 \\
\hline & $\begin{array}{c}56-65 \\
\text { Years }\end{array}$ & semi-illiterates & 16.0 & 0.0 & 2 \\
\hline & & Total & 13.6 & 3.1 & 13 \\
\hline & & Illiterates & 13.6 & 5.4 & 16 \\
\hline & $\begin{array}{c}66-90 \\
\text { Years }\end{array}$ & semi-illiterates & 15.0 & 1.4 & 2 \\
\hline & & Total & 13.7 & 5.1 & 18 \\
\hline & & Illiterates & 14.4 & 4.5 & 45 \\
\hline & Total & semi-illiterates & 14.8 & 2.6 & 10 \\
\hline & & Total & 14.5 & 4.2 & 55 \\
\hline \multirow{12}{*}{ Total } & & Illiterates & 15.4 & 3.7 & 22 \\
\hline & $45-55$ & semi-illiterates & 14.9 & 3.4 & 10 \\
\hline & & Total & 15.2 & 3.6 & 32 \\
\hline & & Illiterates & 13.7 & 3.7 & 21 \\
\hline & $56-65$ & semi-illiterates & 13.2 & 2.7 & 15 \\
\hline & & Total & 13.5 & 3.3 & 36 \\
\hline & & Illiterates & 13.6 & 4.8 & 23 \\
\hline & $66-90$ & semi-illiterates & 14.4 & 3.1 & 7 \\
\hline & & Total & 13.8 & 4.4 & 30 \\
\hline & & Illiterates & 14.2 & 4.2 & 66 \\
\hline & Total & semi-illiterates & 14.0 & 3.0 & 32 \\
\hline & & Total & 14.1 & 3.8 & 98 \\
\hline
\end{tabular}


Table 4. Mean (SD) scores for CERAD verbal fluency (animal naming) test by demographic status.

\begin{tabular}{|c|c|c|c|c|c|}
\hline Sex & Age & Education & Mean & $\begin{array}{c}\text { Standard } \\
\text { deviations }\end{array}$ & Number \\
\hline \multirow{12}{*}{ Male } & \multirow{3}{*}{$45-55$} & Illiterates & 12.7 & 3.8 & 4 \\
\hline & & Semi-illiterates & 11.5 & 2.3 & 4 \\
\hline & & Total & 12.1 & 3.0 & 8 \\
\hline & \multirow{3}{*}{$56-65$} & Illiterates & 11.7 & 3.0 & 10 \\
\hline & & Semi-illiterates & 11.6 & 3.8 & 13 \\
\hline & & Total & 11.7 & 3.4 & 23 \\
\hline & \multirow{3}{*}{$66-90$} & Illiterates & 9.0 & 3.4 & 7 \\
\hline & & Semi-illiterates & 14.2 & 3.8 & 5 \\
\hline & & Total & 11.1 & 4.3 & 12 \\
\hline & \multirow{3}{*}{ Total } & Illiterates & 11.0 & 3.5 & 21 \\
\hline & & Semi-illiterates & 12.2 & 3.6 & 22 \\
\hline & & Total & 11.6 & 3.6 & 43 \\
\hline \multirow{12}{*}{ Female } & \multirow{3}{*}{$45-55$} & Illiterates & 11.6 & 3.6 & 18 \\
\hline & & Semi-illiterates & 12.8 & 5.0 & 7 \\
\hline & & Total & 11.9 & 4.0 & 25 \\
\hline & \multirow{3}{*}{$56-65$} & Illiterates & 10.9 & 3.9 & 11 \\
\hline & & Semi-illiterates & 9.5 & 3.5 & 2 \\
\hline & & Total & 10.6 & 3.8 & 13 \\
\hline & \multirow{3}{*}{$66-90$} & Illiterates & 9.2 & 4.4 & 17 \\
\hline & & Semi-illiterates & 12.5 & 2.1 & 2 \\
\hline & & Total & 9.6 & 4.3 & 19 \\
\hline & \multirow{3}{*}{ Total } & Illiterates & 10.5 & 4.0 & 46 \\
\hline & & Semi-illiterates & 12.1 & 4.3 & 11 \\
\hline & & Total & 10.8 & 4.1 & 57 \\
\hline \multirow{12}{*}{ Total } & \multirow{3}{*}{$45-55$} & Illiterates & 11.8 & 3.6 & 22 \\
\hline & & Semi-illiterates & 12.3 & 4.1 & 11 \\
\hline & & Total & 12.0 & 3.7 & 33 \\
\hline & \multirow{3}{*}{$\begin{array}{c}56-65 \\
\text { Years }\end{array}$} & Illiterates & 11.2 & 3.5 & 21 \\
\hline & & Semi-illiterates & 11.4 & 3.7 & 15 \\
\hline & & Total & 11.3 & 3.5 & 36 \\
\hline & \multirow{3}{*}{$\begin{array}{c}66-90 \\
\text { Years }\end{array}$} & Illiterates & 9.2 & 4.0 & 24 \\
\hline & & Semi-illiterates & 13.7 & 3.4 & 7 \\
\hline & & Total & 10.2 & 4.3 & 31 \\
\hline & \multirow{3}{*}{ Total } & Illiterates & 10.7 & 3.8 & 67 \\
\hline & & Semi-illiterates & 12.2 & 3.8 & 33 \\
\hline & & Total & 11.2 & 3.9 & 100 \\
\hline
\end{tabular}

Independent variables: sex, age and education/illiteracy. Sex is categorized as "male and female," respectively. Age as "45 - 55 years, 56 - 65 years and 66 - 90 years"; education/illiteracy as "illiterates $=0$, semi-illiterates = $1-5$ years”. CERAD: the Consortium to Establish a Registry for Alzheimer's Disease. SD: Standard deviations. 
Table 5. Analysis of variance for main effects and interactions of sex, age and education/illiteracy on the three components of the $10 / 66$ cognitive test battery.

\begin{tabular}{|c|c|c|c|c|}
\hline \multirow{2}{*}{ Test } & \multicolumn{2}{|c|}{ Main effect } & \multicolumn{2}{|c|}{ Interaction } \\
\hline & Variable & $\mathrm{F}, \mathrm{p}$ value $^{*}$ & Variable & $\mathrm{F}, \mathrm{p}$ value $^{\star}$ \\
\hline \multirow{3}{*}{$\begin{array}{c}\text { Global function } \\
\text { (CSI “D” COGSCORE) }\end{array}$} & Sex & $\mathrm{F}=1.816, \mathrm{p}=0.181$ & $\mathrm{SEX}^{*} \mathrm{AGE}$ & $\mathrm{F}=0.903, \mathrm{p}=0.409$ \\
\hline & Age & $\mathrm{F}=0.917, \mathrm{p}=0.403$ & SEX * Edu/Illit & $\mathrm{F}=2.533, \mathrm{p}=0.115$ \\
\hline & Education/illiteracy & $\mathrm{F}=4.67, \mathrm{p}=0.033$ & $\mathrm{AGE}^{\star} \mathrm{Edu} / \mathrm{Illit}$ & $\mathrm{F}=0.090, \mathrm{p}=0.914$ \\
\hline \multirow{3}{*}{ Verbal Fluency } & Sex & $\mathrm{F}=0.499, \mathrm{p}=0.482$ & $\mathrm{SEX}^{*} \mathrm{AGE}$ & $\mathrm{F}=0.052, \mathrm{p}=0.950$ \\
\hline & Age & $\mathrm{F}=0.241, \mathrm{p}=0.786$ & SEX * Edu/Illit & $\mathrm{F}=0.024, \mathrm{p}=0.878$ \\
\hline & Education/illiteracy & $\mathrm{F}=0.443, \mathrm{p}=0.507$ & AGE ${ }^{*}$ Edu/Illit & $\mathrm{F}=0.019, \mathrm{p}=0.981$ \\
\hline \multirow{3}{*}{$\begin{array}{l}\text { Word list } \\
\text { memory }\end{array}$} & Sex & $\mathrm{F}=0.488, \mathrm{p}=0.487$ & $\mathrm{SEX}^{*} \mathrm{AGE}$ & $\mathrm{F}=0.232, \mathrm{p}=0.793$ \\
\hline & Age & $\mathrm{F}=0.597, \mathrm{p}=0.553$ & $\mathrm{SEX}^{*}$ Edu/Illit & $\mathrm{F}=0.023, \mathrm{p}=0.881$ \\
\hline & Education/illiteracy & $\mathrm{F}=1.367, \mathrm{p}=0.245$ & $\mathrm{AGE}^{*} \mathrm{Edu} / \mathrm{Illit}$ & $\mathrm{F}=2.205, \mathrm{p}=0.116$ \\
\hline
\end{tabular}

Independent variables: sex, age and education/illiteracy. Sex is categorized as "male and female," respectively. Age as "45 - 55 years, 56 - 65 years and 66 - 90 years"; education/illiteracy as "illiterates $=0$, semi-illiterates $=1-5$ years". *analyzed by analysis of variance (ANOVA). CSI "D" COGSCORE: cognitive score of The Community Screening Interview for Dementia (CSI “D”), Edu: education, Illit: illiteracy.

The CERAD Word List Memory performance is not significantly influenced by sex, age or education/illiteracy, as shown in Table 5 (ANOVA tests).

In the CERAD Verbal Fluency (Animal naming) illiterate male subjects performed slightly better than semi-illiterate subjects in the same range of age group (45 - 55 years). The performance of males and females was slightly higher in the $45-55$ years and 56 - 65 years groups in comparison with the older group 66 - 90 years. In the total scores of the CERAD Verbal Fluency (Animal naming), males performed slightly better than females.

The effect of gender, age and education/illiteracy on the CERAD Verbal Fluency (Animal naming) test performance was smaller and not significant as shown in Table 5 (ANOVA tests).

As shown in Table 5, ANOVA tests revealed an insignificant interaction between gender, age and education/illiteracy for all the three cognitive tests: the CSI "D" COGSCORE, CERAD Verbal Fluency (Animal naming) and CERAD Immediate word Recall.

\section{Discussion}

We have provided normative data by sex, age group, and educational level (illiterates and semi-illiterates) for the CSI "D" Global Cognitive Function, CERAD Verbal Fluency (Animal naming) and CERAD Immediate word Recall.

The results of the present study suggest that the cognitive functions assessed by the 10/66 cognitive test battery gradually decline with advancing age, but not significantly. This decline in cognitive function has also been shown for many other neuropsychological tests [4] [11].

With regard to education/illiteracy, the present results suggest that the duration of education affects the performance in the 10/66 cognitive test battery like in most neuropsychological tests, as verified in Population normative data for the 10/66 Dementia Research Group cognitive test battery from Latin America, 
India and China [11].

Analysis in this study revealed that all of the CERAD Verbal Fluency (Animal naming) and CERAD Immediate word Recall were not significantly affected by education/illiteracy; however, in the CSI "D" Global Cognitive Function, the effect was moderately significant.

Consistent with the previous study [11], gender had a weaker and not significant influence on the tests performances, and can probably be safely ignored when constructing reference norms [11].

A comparison between the present study results and Population normative data for the 10/66 Dementia Research Group cognitive test battery from Latin America, India and China.

Our normative data compared to norms from Latin America, India and China [11] samples with comparable age (61 \pm 6.80 years), sex and education (Illiterates and semi-illiterates), for the CSI "D" Global Cognitive Function, CERAD Verbal Fluency (Animal naming) and CERAD Immediate word Recall. The results are comparable and well aligned (Tables 6-8).

Table 6. Mean (SD) scores for global cognitive function (CSI "D" COGSCORE) by demographic status and country.

\begin{tabular}{|c|c|c|c|c|c|c|c|c|c|c|c|c|}
\hline \multirow{2}{*}{ Country } & \multirow{2}{*}{$\begin{array}{c}\text { Cuba } \\
\text { Urban }\end{array}$} & \multirow{2}{*}{$\frac{\text { DR }}{\text { Urban }}$} & \multicolumn{2}{|c|}{ Peru } & \multirow{2}{*}{$\begin{array}{c}\text { Venezuela } \\
\text { Urban }\end{array}$} & \multicolumn{2}{|c|}{ Mexico } & \multicolumn{2}{|c|}{ China } & \multicolumn{2}{|c|}{ India } & \multirow{2}{*}{ Morocco } \\
\hline & & & Urban & Rural & & Urban & Rural & Urban & Rural & Urban & Rural & \\
\hline \multicolumn{13}{|l|}{ Age } \\
\hline $61 \pm 6.80$ & $31.1(1.9)$ & $30.4(2.3)$ & $31.8(1.3)$ & $30.6(2.9)$ & $31.1(1.8)$ & $30.8(1.7)$ & $29.8(2.1)$ & $31.7(1.2)$ & $31.0(3.9)$ & $29.2(3.0)$ & $27.9(3.2)$ & $30.23(1.73)$ \\
\hline \multicolumn{13}{|l|}{ Sex } \\
\hline Females & $30.4(2.3)$ & $29.6(2.6)$ & $31.0(2.2)$ & $29.9(2.7)$ & $30.4(1.89)$ & $29.9(2.5)$ & $29.0(2.5)$ & $31.2(2.3)$ & $30.2(3.1)$ & $27.9(3.4)$ & $26.0(5.3)$ & $29.71(1.7)$ \\
\hline Males & $\begin{array}{l}30.7 \\
(2.1)\end{array}$ & $30.2(2.01)$ & $\begin{array}{l}31.1 \\
(2.9)\end{array}$ & $\begin{array}{l}30.2 \\
(3.0)\end{array}$ & $\begin{array}{c}30.7 \\
(2.54)\end{array}$ & $\begin{array}{l}30.2 \\
(2.5)\end{array}$ & $\begin{array}{l}29.2 \\
(2.7)\end{array}$ & $\begin{array}{l}31.6 \\
(1.2)\end{array}$ & $\begin{array}{l}30.7 \\
(4.3)\end{array}$ & $\begin{array}{l}29.7 \\
(3.1)\end{array}$ & $28.5(2.52)$ & $\begin{array}{l}30.92 \\
(1.43)\end{array}$ \\
\hline \multicolumn{13}{|l|}{ Edu/illit } \\
\hline No education & $28.3(3.7)$ & $28.2(3.1)$ & $28.7(3.1)$ & $27.9(3.7)$ & $29.1(1.9)$ & $28.5(2.7)$ & $27.8(3.3)$ & $30.6(2.7)$ & $30.1(3.5)$ & $27.0(3.3)$ & $26.1(5.0)$ & $29.83(1.72)$ \\
\hline $\begin{array}{c}\text { Some } \\
\text { education (did } \\
\text { not complete } \\
\text { primary) }\end{array}$ & $29.3(2.5)$ & $29.8(2.2)$ & $29.8(2.6)$ & $29.9(2.2)$ & $29.7(2.3)$ & $29.5(2.9)$ & $29.4(2.1)$ & $30.7(1.4)$ & $30.3(3.5)$ & $29.0(3.3)$ & $28.5(1.9)$ & $31.05(1.47)$ \\
\hline
\end{tabular}

Table 7. Mean (SD) scores for CERAD verbal fluency (animal naming) test by demographic status and country.

\begin{tabular}{|c|c|c|c|c|c|c|c|c|c|c|c|c|}
\hline \multirow{2}{*}{ Country } & \multirow{2}{*}{$\begin{array}{l}\text { Cuba } \\
\text { Urban }\end{array}$} & \multirow{2}{*}{$\begin{array}{c}\text { DR } \\
\text { Urban }\end{array}$} & \multicolumn{2}{|c|}{ Peru } & \multirow{2}{*}{$\begin{array}{c}\text { Venezuela } \\
\text { Urban }\end{array}$} & \multicolumn{2}{|c|}{ Mexico } & \multicolumn{2}{|c|}{ China } & \multicolumn{2}{|c|}{ India } & \multirow{2}{*}{ Morocco } \\
\hline & & & Urban & Rural & & Urban & Rural & Urban & Rural & Urban & Rural & \\
\hline \multicolumn{13}{|l|}{ Age } \\
\hline $61 \pm 6.80$ & $18.1(6.2)$ & $15.0(4.8)$ & $19.3(5.5)$ & $17.1(4.9)$ & $20.1(6.3)$ & $16.9(5.1)$ & $14.9(4.2)$ & $17.3(4.6)$ & $16.2(5.7)$ & $8.9(3.3)$ & $10.4(3.6)$ & 14.18 \\
\hline \multicolumn{13}{|l|}{ Sex } \\
\hline Females & $15.9(5.6)$ & $13.5(4.5)$ & $17.2(5.3)$ & $15.6(4.7)$ & $18.1(6.2)$ & $15.5(5.1)$ & $13.5(4.3)$ & $16.1(4.6)$ & $14.8(5.1)$ & $8.1(3.1)$ & $9.3(3.7)$ & $14.53(4.21)$ \\
\hline Males & $17.7(6.3)$ & $14.6(5.1)$ & $17.8(5.9)$ & $16.2(5.0)$ & $18.7(6.6)$ & $16.1(5.2)$ & $14.4(4.7)$ & $17.4(4.6)$ & $15.9(5.9)$ & $9.4(3.5)$ & $10.7(3.6)$ & $13.74(3.35)$ \\
\hline \multicolumn{13}{|l|}{ Edu/illit } \\
\hline No education & $13.6(4.5)$ & $12.8(4.3)$ & $14.3(4.5)$ & $13.4(4.1)$ & $14.8(5.0)$ & $14.0(4.4)$ & $12.6(4.0)$ & $15.3(4.4)$ & $14.3(5.1)$ & $7.7(3.1)$ & $9.3(3.6)$ & $14.27(4.21)$ \\
\hline $\begin{array}{c}\text { Some } \\
\text { education (did } \\
\text { not complete } \\
\text { primary) }\end{array}$ & $13.9(5.0)$ & $13.4(4.4)$ & $14.7(4.6)$ & $15.7(5.0)$ & $16.7(6.6)$ & $14.5(4.7)$ & $14.1(4.5)$ & $15.2(5.1)$ & $14.3(5.1)$ & $8.9(3.4)$ & $10.3(3.3)$ & $14.00(3.04)$ \\
\hline
\end{tabular}


Table 8. Mean (SD) scores for CERAD word list memory (immediate recall) test by demographic status and country.

\begin{tabular}{|c|c|c|c|c|c|c|c|c|c|c|c|c|}
\hline \multirow{2}{*}{ Country } & \multirow{2}{*}{$\begin{array}{l}\text { Cuba } \\
\text { Urban }\end{array}$} & \multirow{2}{*}{$\begin{array}{c}\text { DR } \\
\text { Urban }\end{array}$} & \multicolumn{2}{|c|}{ Peru } & \multirow{2}{*}{$\begin{array}{c}\text { Venezuela } \\
\text { Urban }\end{array}$} & \multicolumn{2}{|c|}{ Mexico } & \multicolumn{2}{|c|}{ China } & \multicolumn{2}{|c|}{ India } & \multirow{2}{*}{ Morocco } \\
\hline & & & Urban & Rural & & Urban & Rural & Urban & Rural & Urban & Rural & \\
\hline \multicolumn{13}{|l|}{ Age } \\
\hline $61 \pm 6.80$ & $17.0(3.9)$ & $15.07(3.65)$ & $16.9(3.8)$ & $14.0(3.8)$ & $16.3(4.0)$ & $15.0(3.6)$ & $13.7(3.6)$ & $18.7(4.2)$ & $15.5(4.3)$ & $13.5(4.8)$ & $8.9(3.9)$ & $14.18(3.85)$ \\
\hline \multicolumn{13}{|l|}{ Sex } \\
\hline Males & $15.5(4.0)$ & $13.5(3.9)$ & $14.5(4.0)$ & $12.3(3.72)$ & $14.9(4.1)$ & $12.5(4.3)$ & $11.5(3.9)$ & $18.3(4.5)$ & $14.8(4.5)$ & $13.0(4.9)$ & $8.5(3.7)$ & $13.74(3.35)$ \\
\hline \multicolumn{13}{|l|}{ Edu/illit } \\
\hline No education & $13.4(4.9)$ & $13.0(3.8)$ & $12.3(4.7)$ & $10.6(3.49)$ & $12.1(4.0)$ & $11.7(3.8)$ & $11.3(3.6)$ & $16.3(4.0)$ & $13.8(3.9)$ & $11.0(4.3)$ & $7.2(3.8)$ & $14.11(4.58)$ \\
\hline $\begin{array}{c}\text { Some } \\
\text { education (did } \\
\text { not complete } \\
\text { primary) }\end{array}$ & $13.9(4.0)$ & $13.5(3.7)$ & $13.1(3.7)$ & $12.8(3.91)$ & $14.5(4.3)$ & $12.2(3.8)$ & $12.5(3.9)$ & $16.1(3.7)$ & $14.1(4.1)$ & $12.2(4.1)$ & $8.8(3.5)$ & $13.88(2.99)$ \\
\hline
\end{tabular}

DR = Dominican Republic. Edu: education, Illit: illiteracy.

\section{Conclusions}

Most studies of dementia and mild cognitive impairment (MCI) have been conducted in high-income, developed countries. However, additional challenges exist in trying to assess ethnically diverse populations in developing countries, where the life expectancy is increasing even more rapidly than that in developed countries and the global burden of AD is expected to be even [1] [3] [26].

Because of these facts and also because $\mathrm{AD}$ is defined by its cognitive symptoms, our study has been designed to have a Moroccan version of the 10/66 Dementia Research Group cognitive test battery, in order to facilitate epidemiological research into the etiology and impact of dementia and cognitive decline.

Our results demonstrate the adaptability and utility of the three components of the 10/66 cognitive test battery to assess cognitive decline in illiterate and semi-illiterate Moroccan subjects. These preliminary normative data will be useful for clinical interpretations, early detection of cognitive impairment, and to conduct research in Morocco.

Similar normative study and validation of the 10/66 cognitive test battery involving more age groups and levels of education will help to enhance the dementia diagnosis within illiterate and literate elderly Moroccan subjects.

\section{Acknowledgements}

We appreciate participants (they are all volunteers and non-remunerated) for their cooperation to advance scientific research in our country. This study carried out without any financial commitment by an organization or a person.

\section{Conflicts of Interest}

The authors declare no conflicts of interest regarding the publication of this paper. 


\section{References}

[1] Alzheimer's Disease International (2018) World Alzheimer Report 2018. London. https://www.alz.co.uk/research/WorldAlzheimerReport2018.pdf

[2] WHO (2015) The Epidemiology and Impact of Dementia: Current State and Future Trends. World Health Organization, Geneva.

http://www.who.int/mental_health/neurology/dementia/dementia_thematicbrief_e pidemiology.pdf

[3] Prince, M., Wimo, A., Guerchet, M., Ali, G.C., Wu, Y. and Prina, M. (2015) World Alzheimer Report 2015. The Global Impact of Dementia: An Analysis of Prevalence, Incidence, Cost and Trends. Alzheimer's Disease International, London.

[4] Mukadam, N., et al. (2019) Population Attributable Fractions for Risk Factors for Dementia in Low-Income and Middle-Income Countries: An Analysis Using Cross-Sectional Survey Data. The Lancet Global Health, 7, e596-603. https://doi.org/10.1016/S2214-109X(19)30074-9

[5] United Nations (2015) Department of Economic and Social Affairs, World Population Prospects: The 2015 Revision.

[6] Note d'information du Haut-Commissariat au Plan à l'occasion de la journée internationale des personnes âgées du 1 octobre 2017.

https://www.hcp.ma/Note-d-information-du-Haut-Commissariat-au-Plan-a-l-occas ion-de-la-journee-internationale-des-personnes-agees-du-1_a2019.html

[7] United Nations (2017) World Population Prospects: The 2017 Revision.

[8] ESCWA (2018) Population and Development Report, Issue No. Ageing with Dignity in the Arab Region. http://www.unescwa.org/file/81776/download?token=3_OyjnRA

[9] Fihri, M.F. (2019) Démographie maghrébine Situation et perspectives. Les Cahiers du Plan No. 52 Mai 2019 Haut Commissariat au Plan. Edition Impression Bouregreg, Rabat.

[10] Pei, J.-J., Giron, M.S.T., Jia, J. and Wang, H.-X. (2014) Dementia Studies in Chinese Populations. Neuroscience Bulletin, 30, 207-216. http://www.neurosci.cn/ https://doi.org/10.1007/s12264-013-1420-1

[11] Benabdeljlil, M., Boutbibe, F., Rahmani, M., Benbelaïd, F., Bennani, M., Aïdi, S. and El Alaoui Faris, M. (2015) Dementia and Alzheimer's Disease (AD). Experience of the Memory Center of Rabat. Journal of the Neurological Sciences, 357, e120-e141. https://doi.org/10.1016/j.jns.2015.08.401

[12] Sweeney, M.D., et al. (2019) Vascular Dysfunction-The Disregarded Partner of Alzheimer's Disease. Alzheimer's \& Dementia, 15, 158-167.

https://doi.org/10.1016/j.jalz.2018.07.222

[13] Alzheimer's Dementia in Morocco 2017. http://causesofdeathin.com/alzheimers-dementia-in-morocco

[14] Kang, S.G., et al. (2015) Normative Study of the Literacy Independent Cognitive Assessment in Illiterate and Literate Elderly Koreans. Psychiatry Investigation, 12, 305-315. https://doi.org/10.4306/pi.2015.12.3.305

[15] Alzheimer's Association (2019) Alzheimer's Disease Facts and Figures. Alzheimer's \& Dementia, 15, 321-387. https://doi.org/10.1016/j.jalz.2019.01.010

[16] Baumgart, M., et al. (2015) Summary of the Evidence on Modifiable Risk Factors for Cognitive Decline and Dementia: A Population-Based Perspective. Alzheimer's \& Dementia, 11, 718-726. https://doi.org/10.1016/j.jalz.2015.05.016

[17] Pérès, K., et al. (2017) Trends in the Prevalence of Dementia in French Farmers 
from Two Epidemiological Cohorts. Journal of the American Geriatrics Society, 65, 415-420. https://doi.org/10.1111/jgs.14575

[18] Satizabal, C.L., Beiser, A.S., Chouraki, V., Chêne, G., Dufouil, C. and Seshadri, S. (2016) Incidence of Dementia over Three Decades in the Framingham Heart Study.

The New England Journal of Medicine, 374, 523-532.

https://doi.org/10.1056/NEJMoa1504327

[19] American Psychiatric Association (1994) Diagnostic and Statistical Manual of Mental Disorders. 4th Edition, AMA, Washington DC.

[20] Manly, J.J., Jacobs, D.M., Sano, M., Bell, K., Merchant, C.A., Small, S.A., et al. (1999) Effect of Literacy on Neuropsychological Test Performance in Non Demented, Education-Matched Elders. Journal of the International Neuropsychological Society, 5, 191-202. https://doi.org/10.1017/S135561779953302X

[21] Sosa, A., Prince, M., Guerra, M., de Rodriguez, J., Gaona, C., Rodriguez, G. and Williams, J. (2009) Population Normative Data for the 10/66 Dementia Research Group Cognitive Test Battery from Latin America, India and China: A Cross-Sectional Survey. BMC Neurology, 9, 48.

https://doi.org/10.1186/1471-2377-9-48

[22] Population légale des régions, provinces, préfectures, municipalités, arrondissements et communes du royaume d'après les résultats du rgph 2014. High Commission for Planning, Morocco. (In Arabic and French)

[23] Hall, K.S., Hendrie, H.C., Brittain, H.M., Norton, J.A., Rodgers, D.D., Prince, C.S., Pillay, N., Blue, A.W., Kaufert, J.N., Nath, A., et al. (1993) The Development of a Dementia Screening Interview in Two Distinct Languages. International Journal of Methods in Psychiatric Research, 3, 1-28.

[24] Hall, K.S., Gao, S., Emsley, C.L., Ogunniyi, A.O., Morgan, O. and Hendrie, H.C. (2000) Community Screening Interview for Dementia (CSI D); Performance in Five Disparate Study Sites. International Journal of Geriatric Psychiatry, 15, 521-531. https://doi.org/10.1002/1099-1166(200006)15:6<521::AID-GPS182>3.0.CO;2-F

[25] Prince, M., Acosta, D., Chiu, H., Scazufca, M. and Varghese, M. (2003) Dementia Diagnosis in Developing Countries: A Cross-Cultural Validation Study. The Lancet, 361, 909-917. https://doi.org/10.1016/S0140-6736(03)12772-9

[26] Silverberg, et al. (2011) Assessment of Cognition in Early Dementia. Alzheimer's \& Dementia, 7, e60-e76. https://doi.org/10.1016/j.jalz.2011.05.001 